\title{
Comparison of detection procedures for Chlamydia trachomatis, including enzyme immunoassays, in a mouse model of genital infection
}

\author{
D. TAYLOR-ROBINSON and M.TUFFREY
}

\section{Division of Sexually Transmitted Diseases, Clinical Research Centre, Watford Road, Harrow, Middlesex, HA1 3UJ}

\begin{abstract}
Summary. Two chlamydial enzyme immunoassays, Chlamydiazyme ${ }^{\circledR}$ and IDEIA, ${ }^{\circledR}$ were evaluated in a mouse model of chlamydial genital-tract infection. The Chlamydiazyme assay and the IDEIA were assessed on specimens from 10 and 11 mice, respectively. The animals were infected with Chlamydia trachomatis, strain $\mathrm{SA}_{2} \mathrm{f}$, and the results obtained by these methods on vaginal specimens taken on 4 or 5 occasions during 41-42 days were compared with those obtained in cell culture and to a less extent by the MicroTrak ${ }^{\circledR}$ direct immunofluorescence test. In comparison with culture, the Chlamydiazyme assay had a sensitivity of $62 \%$ and a specificity of $92 \%$; IDEIA had a sensitivity of $76 \%$ and a specificity of $94 \%$. These assays sometimes did not detect chlamydiae in specimens taken immediately before specimens which proved positive by culture and the immunoassays were less sensitive if swabs were taken after those for culture. The IDEIA also failed to detect chlamydiae in the late stage of the murine infection when chlamydial elementary bodies were seen by immunofluorescence. The implications of the observations for investigations in the human field as well as for further studies in the mouse are discussed.
\end{abstract}

\section{Introduction}

Methods available for the detection of Chlamydia trachomatis organisms (chlamydiae) comprise cultural procedures, staining of elementary bodies with fluorescent monoclonal antibodies and, more recently, enzyme immunoassays. The methods have been evaluated by testing specimens from patients who are then usually treated, precluding the possibility of following infection by taking sequential specimens. Animal models of chlamydial infection, however, are not restricted in this way. Thus, female mice given inocula of $C$. trachomatis in the genital tract sustain an infection which, although self-limited, persists for several weeks (Tuffrey et al., 1982). This enables vaginal specimens from numerous animals to be collected easily over a prolonged period in a sequential fashion, providing an outstanding opportunity to compare the sensitivity and specificity of the various chlamydial detection methods. In this way, we have evaluated two commercially available enzyme immunoassays (Chlamydiazyme ${ }^{\circledR}$ and IDEIA ${ }^{\circledR}$ ), comparing their performance with that of a cultural procedure and also IDEIA to some extent with a

Received 21 Nov. 1986; accepted 2 Jan. 1987. direct fluorescent antibody technique (Micro$\left.\operatorname{Trak}^{\circledR}\right)$.

\section{Materials and methods}

\section{Mice}

Specific pathogen-free outbred TO female mice, 9 weeks old, from the Pathogen-free Unit at the Clinical Research Centre (CRC) were maintained in the Infectious Suite at the CRC.

\section{Infection of mice}

The mice were treated with progesterone (DepoProvera; Upjohn) and were given inocula of $1 \times 10^{6}$ inclusion-forming units of the LGV-2 serovar $\mathrm{SA}_{2} \mathrm{f}$ of $C$. trachomatis suspended in sucrose-phosphate medium via the right uterine horn, as described previously (Tuffrey and Taylor-Robinson, 1981). Each mouse was ear-tagged for identification.

\section{Detection procedures for chlamydiae}

Culture. A sterile cotton-wool nasopharyngeal swab (Medical Wire and Equipment Co. Ltd; MW142) was inserted and rotated in the vagina, and then agitated vigorously and expressed in $1.0 \mathrm{ml}$ of cold sucrose- 
phosphate transport medium (2SP) containing $10 \%$ heatinactivated fetal calf serum. Specimens were stored in liquid nitrogen until inoculated into cycloheximidetreated McCoy-cell cultures and the inclusions were stained with Giemsa, as described previously (Thomas et al., 1977). Two monolayers of cells were used for each specimen and the results are shown as the number of chlamydial inclusions per monolayer.

Monoclonal fluorescent antibody direct test (MicroTrak; Syva). Nasopharyngeal swabs were inserted in the vagina, rotated and then rolled on the marked area of the slide. The fixing of these smears, and their examination after treatment with the 'MicroTrak Chlamydia trachomatis direct fluorescent antibody reagent', were undertaken as described previously (Thomas et al., 1984), as was the counting and recording of the numbers of elementary bodies (EBs) in the smears.

Enzyme-linked immunosorbent assay (Chlamydiazyme; Abbott). This assay is based on a rabbit antichlamydial polyclonal antibody and a peroxidase substrate. Specimens were taken with the 'Chlamydiazyme' swab provided and were kept at $4^{\circ} \mathrm{C}$ for no longer than 3 days. The assay was performed according to the manufacturer's instructions and exactly as described previously (TaylorRobinson et al., 1987) with a multichannel automatic washing device (the Abbott Proquantum system). As controls, a positive specimen and negative specimens supplied in the kit were included in each assay and its successful performance was based on the results for these specimens fulfilling the manufacturer's stated values.

Amplified enzyme-linked immunoassay (IDEIA; Boots Celltech). This assay is based on a mouse antichlamydial monoclonal antibody and an alkaline phosphatase substrate with an alcohol oxidoreductase-diaphorase amplification (Pugh et al., 1985). Vaginal specimens were taken as previously (Tuffrey and Taylor-Robinson, 1981) with nasopharyngeal swabs which were cut off into $1.0 \mathrm{ml}$ of the specially supplied transport medium in 1-ml glass vials. These specimens were stored at $4^{\circ} \mathrm{C}$ for no longer than 3 days and were processed and the results recorded exactly according to the manufacturer's instructions. As controls, a positive specimen and negative specimens supplied in the kit were included in each assay and the results were obtained as a print-out from a standard ELISA reader.

\section{Experimental procedures}

Experiment 1. Ten mice were inoculated with chlamydiae and together with eight uninoculated mice, serving as controls, were used to assess the value of the Chlamydiazyme assay in comparison with chlamydial culture. On days 5, 19,27, 35 and 42 after inoculation, swabs were taken separately for each test without the mice being anaesthetised. To minimise sampling error, swabs for the Chlamydiazyme assay were taken first, and those for culture second, from odd-numbered mice on days 5, 27 and 42 and from even-numbered mice on days 19 and 35. The swabs were taken in the reverse order on the other days. To determine whether swabs that were taken first held an advantage, two swabs taken consecutively on day 32 were tested in cell culture.

Experiment 2. Eleven mice inoculated with chlamydiae and seven uninoculated controls were used to assess the value of the IDEIA in comparison with chlamydial culture and the MicroTrak test. Each mouse was swabbed separately for the IDEIA and culture on days $6,11,19$, 25 and 41 after inoculation, the swabs for the IDEIA being taken first, and those for culture second, only on the days indicated in table II. Swabs for the MicroTrak test were taken on days 15,22 and 41 after inoculation.

\section{Assessment of the value of immunoassays in comparison with culture}

The following formulae were used:

$$
\begin{aligned}
\text { Sensitivity }= & \frac{\begin{array}{c}
\text { number of specimens positive } \\
\text { by both assay and culture }
\end{array}}{\text { number of specimens positive by culture }} \\
\text { Specificity }= & \frac{\begin{array}{c}
\text { number of specimens negative } \\
\text { by both assay and culture }
\end{array}}{\text { number of specimens negative by culture }}
\end{aligned}
$$

Positive predictive value (PPV)

number of specimens positive

$$
=\frac{\text { by both assay and culture }}{\text { number of specimens positive by assay }}
$$

Negative predictive value (NPV)

$$
\begin{array}{r}
\text { number of specimens negative } \\
\qquad=\frac{\text { by both assay and culture }}{\text { number of specimens negative by assay }}
\end{array}
$$

\section{Results}

\section{Chlamydiazyme assay compared with culture}

The results of the first experiment are shown in table I. Chlamydiae were isolated from all of the 10 mice 5 days after inoculation and then from a progressively smaller number so that only three mice were culture-positive 42 days after inoculation. The Chlamydiazyme assay was also positive most often 5 days after inoculation, but the number of positive results diminished more rapidly. Overall, of the 29 occasions on which chlamydiae were isolated, the Chlamydiazyme assay was positive on only 18 occasions. Chlamydiae were not isolated from any of the eight uninoculated mice on the single occasion on which they were tested and none of the 40 specimens taken from these control animals during the course of the experiment gave positive results in the assay. Thus, the Chlamydiazyme assay, in comparison with culture, had a sensitivity of $62 \%$, a specificity of $92 \%$, a PPV of $90 \%$, and a NPV of $69 \%$.

The results of testing by culture two consecutive 
Table I. Results of attempts to detect chlamydial strain $\mathrm{SA}_{2} \mathrm{f}$ by Chlamydiazyme and in culture

\begin{tabular}{|c|c|c|c|c|c|c|c|c|c|c|c|}
\hline \multirow{3}{*}{$\begin{array}{c}\text { Mouse } \\
\text { no. }\end{array}$} & \multicolumn{11}{|c|}{$\begin{array}{c}\text { Result of Chlamydiazyme (Ch.) assay and number of inclusions in culture (Cult.) produced by specimens taken } \\
\text { on indicated day after mouse inoculation }\end{array}$} \\
\hline & \multicolumn{2}{|c|}{5} & \multicolumn{2}{|c|}{19} & \multicolumn{2}{|c|}{27} & \multirow{2}{*}{$\begin{array}{r}32 \\
\text { Cult. }\end{array}$} & \multicolumn{2}{|c|}{35} & \multicolumn{2}{|c|}{42} \\
\hline & Ch. & Cult. & $\mathrm{Ch}$. & Cult. & $\mathrm{Ch}$. & Cult. & & Ch. & Cult. & Ch. & Cult. \\
\hline 1 & + & 324 & - & 4 & - & 0 & 0,0 & - & 0 & - & NT \\
\hline 2 & + & 1 & + & 0 & - & 0 & 0,0 & - & 0 & - & NT \\
\hline 3 & + & 175 & - & 0 & - & NT & 0,0 & - & 30 & - & 3 \\
\hline 4 & - & 69 & + & 3 & - & 168 & 2,4 & - & 0 & - & 0 \\
\hline 5 & + & 5 & - & 4 & - & 93 & 208,67 & - & 73 & + & $>250$ \\
\hline 6 & + & $>250$ & + & 0 & - & 11 & 0,0 & - & 0 & - & 0 \\
\hline 7 & + & 207 & - & 116 & + & 71 & $>250,31$ & + & 3 & - & 0 \\
\hline 8 & + & 85 & + & 85 & + & 3 & 0,0 & - & 0 & - & 0 \\
\hline 9 & + & 63 & - & 313 & + & 5 & $>250,32$ & + & $>250$ & + & 8 \\
\hline 10 & + & 3 & - & 0 & - & 0 & 0,0 & - & 0 & - & 0 \\
\hline Controls* & & & & & & & & & & & \\
\hline $11-18$ & - & 0 & - & & - & & - & - & & - & \\
\hline
\end{tabular}

NT = no test (cell monolayers destroyed).

* Controls not swabbed for culture of chlamydiae after day 5.

vaginal swabs taken on day 32 (table $I$ ) showed that the isolation rate was not diminished by a second swabbing but, generally, fewer inclusions were demonstrable. Testing of the swab taken second rather than first also reduced the sensitivity of the Chlamydiazyme assay. Thus, in the main comparative tests on the other 5 days, the overall sensitivity of the assay was reduced from $84.6 \%$ for the swabs taken first to $44 \%$ for those taken second. Despite inferior sensitivity, the assay was positive on two occasions when chlamydiae were not recovered in culture. One of these results (mouse no. 6; day 19) was probably a true positive because chlamydiae were isolated from the same mouse one week later. The other (mouse no. 2; day 19) may have been a false positive result, but, as noted previously, such results were not seen in the control group.

\section{Amplified immunoassay (IDEIA) compared with culture and with MicroTrak}

The results of the second experiment, except for those by MicroTrak, are shown in table II. Of the 38 occasions on which chlamydiae were isolated from the 11 inoculated mice, the IDEIA was positive on 29 occasions; in three instances when attempts to culture failed because of disruption of the cell monolayers, the IDEIA was positive and in two cases subsequent tests indicated that the culture results were falsely negative. Chlamydiae were not isolated from any of the seven uninoculated mice on the two occasions on which they were tested and none of 28 tests on these control mice by the IDEIA proved positive. Overall, IDEIA in comparison with culture had a sensitivity of $76 \%$, a specificity of $94 \%$, a PPV of $97 \%$ and a NPV of $64 \%$. However, the sensitivity of the IDEIA was $84 \%$ if the swabs for this test were taken first, and $68 \%$ if they were taken second.

The MicroTrak test was positive on specimens from all mice on days 15 and 22 after inoculation. On day 41 after inoculation, chlamydiae were seen usually in small numbers ( $<10 \mathrm{EBs})$ in smears from six of the 11 mice but were not detected by the IDEIA in any of them.

\section{Discussion}

The order in which swabs are taken is always an important issue in comparative tests. There were five instances in the mouse experiments where a swab taken first for one or other of the immunoassays gave a negative result whereas that taken second for culture gave a positive result, and only one instance where the reverse was true. It is not surprising, therefore, that taking a specimen from the mouse vagina for the immunoassays immediately after a specimen for culture proved less sensitive than taking it first. Of course, a swab taken second is inevitably at a disadvantage compared with that taken first and legitimate assessment of sensitivity must, therefore, be based, as presented here, on the results of all swabbings in 
Table II. Results of attempts to detect chlamydial strain $\mathrm{SA}_{2} \mathrm{f}$ by IDEIA and in culture

\begin{tabular}{|c|c|c|c|c|c|c|c|c|}
\hline \multirow{3}{*}{$\begin{array}{c}\text { Mouse } \\
\text { no. }\end{array}$} & \multicolumn{8}{|c|}{$\begin{array}{l}\text { Results of IDEIA and number of inclusions in culture (Cult.) produced by } \\
\text { specimens taken on indicated day after mouse inoculation }\end{array}$} \\
\hline & \multicolumn{2}{|c|}{7} & \multicolumn{2}{|c|}{11} & \multicolumn{2}{|c|}{19} & \multicolumn{2}{|c|}{25} \\
\hline & IDEIA & Cult. & IDEIA & Cult. & IDEIA & Cult. & IDEIA & Cult. \\
\hline 1 & - & 1 & $-*$ & 0 & + & 0 & $t^{*}$ & 1 \\
\hline 2 & $+^{*}$ & 1 & + & 3 & $-^{*}$ & 94 & + & $>250$ \\
\hline 3 & + & 222 & $+^{*}$ & 296 & + & $>500$ & $+^{*}$ & NT \\
\hline 4 & + & 1 & $+^{*}$ & NT & - & $>250$ & $+^{*}$ & 38 \\
\hline 5 & $+*$ & 2 & - & 49 & $+^{*}$ & 13 & - & 89 \\
\hline 6 & + & 243 & $+^{*}$ & 3 & + & 31 & $+^{*}$ & $>250$ \\
\hline 7 & $+^{*}$ & 2 & + & 2 & $-*$ & $>500$ & + & \\
\hline 8 & + & 3 & + & 4 & - & 319 & $t^{*}$ & $>250$ \\
\hline 9 & $+^{*}$ & 6 & $t^{*}$ & 3 & $t^{*}$ & 98 & + & 3 \\
\hline 10 & $t^{*}$ & 75 & $+^{*}$ & 125 & - & 30 & $+^{*}$ & 68 \\
\hline 11 & - & 0 & + & NT & $-^{*}$ & 72 & + & 100 \\
\hline Controls ${ }^{\dagger}$ & & & & & & & & \\
\hline $12-18$ & - & 0 & - & 0 & - & & - & \\
\hline
\end{tabular}

which those taken first alternate with those taken second. However, no such difference was seen in the human situation between first and second genital swabs tested in the Chlamydiazyme assay (Taylor-Robinson et al., 1987), possibly because of the larger mucosal surface swabbed and the availability of more material. Nevertheless, the observation in the mice does indicate the importance of randomising the order of swabbing in evaluating tests in the human clinical field.

Our finding that the Chlamydiazyme assay was less sensitive than culture for detecting chlamydiae in the mouse vagina was in agreement with the results of tests on human genital specimens in which the same assay was less sensitive than either the MicroTrak test or culture and was considered unsatisfactory for testing such specimens (TaylorRobinson et al., 1987). Use of the IDEIA rather than the Chlamydiazyme assay enhanced somewhat the ability to detect chlamydial antigen in the mice. However, the magnitude of the increased sensitivity does not suggest that the IDEIA, despite its amplification system, is likely to be the complete answer to the successful testing of human specimens for chlamydiae, despite some encouraging reports (Caul and Paul, 1985; Pugh et al., 1985; Sherwood, 1986). The Chlamydiazyme assay was not compared with the MicroTrak test on specimens from the mice but the IDEIA failed to detect chlamydiae in the late stage of the murine infection when EBs were seen by immunofluorescence. This again points to the potential problem that may exist in testing human specimens.

The specificity of the Chlamydiazyme assay was superior to its sensitivity in the mouse model, a result again in agreement with that obtained with human clinical specimens (Taylor-Robinson et al., 1987). The specificity of tests on mice may be attributable to the use of specific pathogen-free animals. It is difficult to assess whether the specificity of the IDEIA might prove greater than that of Chlamydiazyme for testing human specimens on the basis of our findings in the mouse model since the mouse is free of human genitaltract bacteria that are known to be cross-reactive (Taylor-Robinson et al., 1987). However, the fact that the IDEIA is based on a monoclonal rather than a polyclonal antibody may be to its advantage.

These observations on the mouse model have implications not only for the human field, as discussed, but also for further studies on the model. In both situations, cultural procedures are labourintensive and time-consuming and detection of chlamydiae directly by means of fluorescent antibodies is fatiguing over long periods. However, because both the Chlamydiazyme assay and IDEIA are relatively specific, at least in the mouse model, and longitudinal studies allow occasional discrepancies to be identified, a reasonable strategy for mouse studies might be as follows. The first of two 
consecutive swabs could be tested by an enzyme immunoassay and the second stored and tested subsequently by culture, or immunofluorescence, only if the assay result proved to be negative. If the first experiment described here is taken as an example, this strategy would mean that only half of

\section{REFERENCES}

Caul E O, Paul ID 1985 Monoclonal antibody based ELISA for detecting Chlamydia trachomatis. Lancet $1: 279$.

Pugh S F, Slack R C B, Caul E O, Paul I D, Appleton P N, Gatley S 1985 Enzyme amplified immunoassay: a novel technique applied to direct detection of Chlamydia trachomatis in clinical specimens. Journal of Clinical Pathology 38: 1139-1141.

Sherwood D 1986 Evaluation of an immunofluorescence test and an amplified enzyme immunoassay for the direct detection of Chlamydia trachomatis in urino-genital specimens. In: Oriel D et al. (eds) Chlamydial infections. Cambridge University Press, Cambridge, p 554.

Taylor-Robinson D, Thomas B J, Osborn M F 1987 Evaluation of enzyme immunoassay (Chlamydiazyme) for detecting Chlamydia trachomatis in genital tract specimens. Journal of Clinical Pathology 40: 194-199.

Thomas B J, Evans R T, Hutchinson G R, Taylor-Robinson D the specimens would need to be tested by culture or immunofluorescence.

We thank Mrs Mary Osborn for undertaking the immunofluorescence test and Dr Brenda Thomas for her assistance and for helpful discussion.

1977 Early detection of chlamydial inclusions combining the use of cycloheximide-treated McCoy cells and immunofluorescence staining. Journal of Clinical Microbiology 6: 285-292.

Thomas B J, Evans R T, Hawkins D A, Taylor-Robinson D 1984 Sensitivity of detecting Chlamydia trachomatis elementary bodies in smears by use of a fluorescein labelled monoclonal antibody: comparison with conventional chlamydial isolation. Journal of Clinical Pathology 37: 812-816.

Tuffrey M, Taylor-Robinson D 1981 Progesterone as a key factor in the development of a mouse model for genital-tract infection with Chlamydia trachomatis. FEMS Microbiology Letters 12: 111-115.

Tuffrey M, Falder P, Taylor-Robinson D 1982 Genital-tract infection and disease in nude and immunologically competent mice after inoculation of a human strain of Chlamydia trachomatis. British Journal of Experimental Pathology 63: 539-546. 